\title{
Drug Coated Balloons: Are they the Holy Grail for Dysfunctional Dialysis Arteriovenous Fistulas?
}

\author{
Farah Gillan $\operatorname{Irani}^{1}{ }^{1} \cdot$ Bien Soo $^{\text {Tan }}{ }^{1}$
}

Received: 29 September 2020/Accepted: 13 October 2020/Published online: 6 November 2020

(C) Springer Science+Business Media, LLC, part of Springer Nature and the Cardiovascular and Interventional Radiological Society of Europe (CIRSE) 2020

The recent publication of 6-month results of the IN.PACT AV Access study has brought the use of drug coated balloons (DCB) in the treatment of dysfunctional dialysis arteriovenous fistulas (AVFs) into the spotlight [1].

This global prospective trial randomized 330 patients to either DCB or standard balloon angioplasty (sPTA) following lesion preparation using a high-pressure balloon (HPB). The primary end point was target lesion primary patency (TLPP) based on clinically driven target lesion revascularization (TLR) and safety data for major adverse event at 30 days. The trial was conducted with independent events committee and core lab adjudication. The study achieved its primary end points. The 6-month TLPP was superior in the DCB arm (82.2\% (DCB) vs 59.5\% (sPTA); $p<0.001)$, and these results held true for sensitivity analysis. The primary safety end point showed DCB to be non-inferior to sPTA $(4.2 \%$ vs $4.4 \%$ respectively; $p=0.002)$.

Thus, have we found the Holy Grail for treating dysfunctional AVFs? The results of this study are very similar to those reported in an earlier randomized trial [2] where both TLPP and access circuit primary patency (ACPP) were statistically improved in the DCB cohort at 6 months (TLPP $81 \%$ vs $61 \% p=0.03$; ACPP $76 \%$ vs $56 \%$ $p=0.048)$. While these results are very promising for DCBs, there are several points that we should reflect on.

Farah Gillan Irani

farah.gillan.irani@singhealth.com.sg

1 Division of Radiological Sciences, Department of Vascular and Interventional Radiology, Singapore General Hospital, Block 2 Level 1, Outram Road, Singapore 169608, Singapore
We note that the TLPP in the IN.PACT AV Access trial was based on clinically driven need for reintervention and 6-month ultrasound rather than angiography which is the gold standard. Also, the operators were not blinded to the study device because of the difference in balloon construct. These two factors could have introduced bias into the study.

A similarly constructed randomized FDA device exemption trial using another brand of DCB [3] did not reach its primary end point of improved TLPP at 6 months, although it did show significance in favor of DCB at 210 days. Complete 2-year data analysis showed DCB improved TLPP only at 9 months and not at any other predetermined time period [4]. This raises the question of whether all DCBs are equally effective and highlights the need for head-to-head comparison between different DCBs.

The above 3 trials only treated a single severe clinically relevant lesion or two tandem focal lesions within $3 \mathrm{~cm}$ of each other over a $100 \mathrm{~mm}$ consecutive length. This does not reflect real-world practice, wherein most AVFs have multiple lesions. Hence, trials where all lesions are treated with DCB to see their impact on ACPP as well as costeffectiveness should be undertaken.

HPB angioplasty may also not be the most effective preparation for DCB, as cutting balloon was proven to be superior to HPB angioplasty in prolonging TLPP in resistant lesions [5]. The combination of cutting or scoring balloons with the use of DCB should be explored, to study whether these are more effective in delivering the drug to the medial smooth muscle cells.

All the data so far have shown that paclitaxel DCBs are safe in treating dialysis access lesions with no increase in mortality at 1 and 2 years, and we await the longer-term 
results of ongoing trials. One should not forget the effectiveness of other limus drugs, and studies involving sirolimus DCBs should be performed.

In conclusion, the IN.PACT AV access trial proves the clinical effectiveness of DCB in the treatment of dysfunctional AVFs at 6 months. However, more investigatorinitiated trials looking at safety and longer-term clinical and cost-effectiveness of treating all lesions within the access circuit are needed before we proclaim DCBs as the Holy Grail.

Funding This study was not supported by any funding.

\section{Compliance with Ethical Standards}

Conflict of interest The authors declare they have no conflict of interest.

Consent for Publication The authors give consent for publication.

Ethical Approval For this commentary, no IRB approval is needed.

Informed Consent For this commentary, no informed consent is required.

\section{References}

1. Lookstein RA, Haruguchi H, Oureil K, et al. Drug-coated balloon for dysfunctional dialysis arteriovenous fistulas. New Engl J Med. 2020;383:733-42.

2. Irani FG, Teo TKB, Tay KH, et al. Hemodialysisarteriovenous fistula and graft stenoses: randomized trial comparing drug-eluting balloon angioplasty with conventional angioplasty. Radiology. 2018;289:238-47.

3. Trerotola SO, Lawson J, Roy-Chaudhury P, et al. Drug coated balloon angioplasty in failing AV fistulas. A randomized controlled trial. Clin J Am SocNephrol. 2018;13:1215-24.

4. Trerotola SO, Saad TF, Roy-Chaudhury P. TheLutonix AV randomized trial of paclitaxel-coated balloons in arteriovenous fistula stenosis: 2 year results and subgroup analysis. J VascIntervRadiol. 2020;31:1-14.

5. Aftab SA, Tay KH, Irani FG, et al. Randomized clinical trial of cutting balloon angioplasty versus high-pressure balloon angioplasty in hemodialysisarteriovenous fistula stenoses resistant to conventional balloon angioplasty. J VascIntervRadiol. 2014;25(2):190-8.

Publisher's Note Springer Nature remains neutral with regard to jurisdictional claims in published maps and institutional affiliations. 